\title{
The Electric Power Enterprise Supplier Management and Bidding Procurement Linkage Strategies Applied Research
}

\author{
Yong-Huan HU \\ Purchase Department \\ State Grid Shanghai Municipal Electric Power \\ Company \\ Shanghai, China \\ E-mail: huyh@sh.sgcc.com.cn
}

\author{
Feng-Na DONG \\ QC Department \\ Shanghai JIULONG Enterprise Management Consulting \\ Co. Ltd. \\ Shanghai, China \\ E-mail: fengnadong@126.com
}

\author{
Wei-Jie SHEN \\ Purchase Department \\ Shanghai JIULONG Enterprise Management \\ Consulting Co. Ltd. \\ Shanghai, China \\ E-mail: shenwj@sh.sgcc.com.cn
}

\author{
Xin WANG \\ QC Department \\ Shanghai JIULONG Enterprise Management Consulting \\ Co. Ltd. \\ Shanghai, China \\ E-mail: 1_w_xin@163.com
}

\begin{abstract}
Power grid enterprises supplier relationship management is closely linked with purchasing supply business, complement each other, both the front end of the bidding procurement, and late for supplies to provide further support. Shanghai municipal electric power company centralized purchasing in public bidding way, the winning number of suppliers, the scope is big, especially in the low voltage equipment factory, the quality management level is uneven, weak part of the plant quality management, supply risk. Through supplier management and bidding procurement linkage, further expand the centralized bid procurement, purchasing management specification; Ability to further enhance supplies and improve the supply response speed and service level further; Deepen the material quality control, strictly the quality of equipment entrance, from the source to ensure the quality of power grid construction; To further enhance the level of risk prevention and control, increasing material strength of the supervision and inspection, improve the working mechanism of supervision and inspection, and ensure the quality of bidding procurement, continue to strengthen the company centralized purchasing brand influence.
\end{abstract}

Keywords-the electric power enterprise; supplier management; the bidding procurement; linkage strategies

\section{INTRODUCTION}

In recent years, Shanghai municipal electric power company, based on standard into information to support, in supplier relationship management, for protection, deepening concentration scale procurement, in order to strengthen the management of contract performance and product quality supervision, build a modern logistics system, promote comprehensive support company strategy of "a strong three- excellent" supply chain construction, deepening material intensive management. As an important part of materials of the intensification of, supplier relationship management is closely linked with purchasing supply business, complement each other, both the front end of the bidding procurement, and late for supplies to provide further support. Shanghai municipal electric power company centralized purchasing in public bidding way, the winning number of suppliers, the scope is big, especially in the low voltage equipment factory, the quality management level is uneven, weak part of the plant quality management, supply risk. At the same time, the previous supplier qualification, equipment, production capacity of on-site verification system has not been formed, the lack of a clear scoring rules, can't direct reference in the process of grading, affect the inspection efficiency. Because the expert subjective scores more, are prone to bias the result of the bid evaluation. Through supplier management and bidding procurement linkage, further expand the centralized bid procurement, purchasing management specification; Ability to further enhance supplies and improve the supply response speed and service level further; Deepen the material quality control, strictly the quality of equipment entrance, from the source to ensure the quality of power grid construction; To further enhance the level of risk prevention and control, increasing material strength of the supervision and inspection, improve the working mechanism of supervision and inspection, and ensure the quality of bidding procurement, continue to strengthen the company centralized purchasing brand influence.

Large power grid supplies a wide range of suppliers. With the deepening of the intensive management of supplies, all kinds of problems related to the supplier has increased dramatically, the letter to the supplier selection and evaluation of the existing management system analysis and 
comprehensive combing, further improve the mechanism, streamline work processes, improve work efficiency, and implement comprehensive and efficient supplier management. Since 2005, Shanghai municipal electric power company for some suppliers of bidding, the performance of qualification verification and performance evaluation work, and gradually set up the supplier management system to further strengthen supplier qualification assessment before the net, to carry out the supplier evaluation and performance after coordination. Strengthen the supplier performance management, intensify handling of supplier's misconduct; Supplier information database and risk management for the whole system sharing set up library, avoid the risk of power grid construction and performance. Strengthen the supplier relationship management, and strive to create a harmonious supplier relationships.

\section{APPLICATION RESEARCH ON THEORETICAL BASIS}

Supplier management is developed on the basis of supply chain management, establish the related information to enterprise's suppliers and complete, on the basis of effective management and use, to establish and maintain partnership with suppliers of new management mechanism and system engineering. To strengthen supplier management, according to the characteristics of the electric power enterprise supplier management, establish the corresponding supplier management model, including the supplier qualification evaluation system, the supplier performance evaluation system and the three layer structure of the classification system suppliers. Three layer structure, supplier qualification information collected through regular supplier qualification evaluation system, set up the supplier qualification information database, and then evaluate the supplier qualification information. Supplier performance evaluation system for trade suppliers, have been reported to evaluate each link in the process of the transaction, supplier performance evaluation results are obtained. Supplier classification system adopted the supplier performance evaluation results, combined with the company of the supplier's reliance, in view of the different types of supplier on the corresponding supplier relationship management strategy, the differentiation of relations between the supplier management.

\section{THE ELECTRIC POWER ENTERPRISE SUPPLIER MANAGEMENT AND BIDDING PROCUREMENT LINKAGE STRATEGIES APPLIED RESEARCH}

\section{A. The Overall Framework Design Supplier Management and Bidding Procurement Linkage}

By analysis product quality problem, summary the supplier bad behavior, with reference to supplier performance evaluation result and supplier qualification results to verify the business situation, respectively specific closed-loop linkage application standards. Combing product quality problems dealing with suppliers, bad behavior, qualification performance verification, the supplier performance evaluation results and the relationship between the performance and the linkage of the bidding of the contract, the overall framework design of closed loop linkage. According to the historical purchase amount to determine the key material included in the closed-loop linkage supplies directory, file analysis supplies the assessment, the comparative assessment document with supplier management standards, eventually clear linkage content and way of linkage. See Figure 1.

Figure 1. The overall frame closed-loop linkage

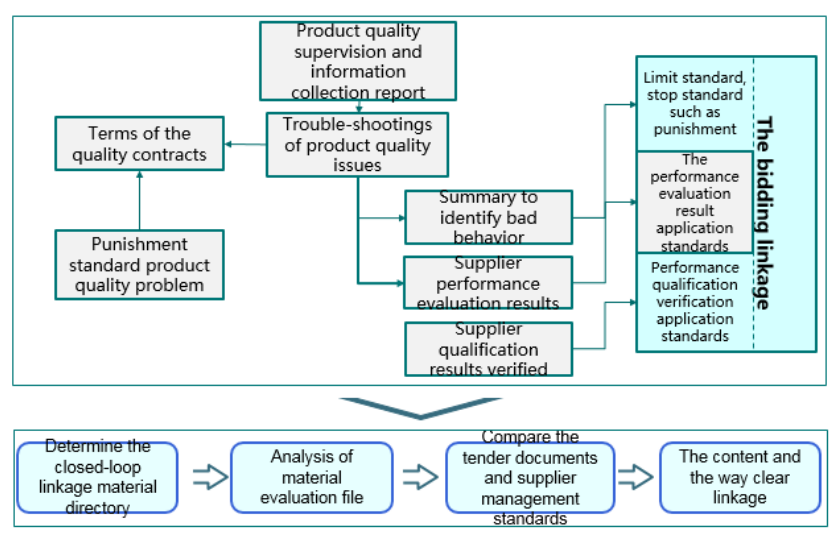

\section{B. Supplier Performance Ability of Qualification}

Verification And Tender Linkage Scheme Design

On supplier qualification verification performance ability, in e-commerce platform to establish a unified supplier information database, the issuance of "performance information to verify proof of qualifications" for the bid evaluation experts accurately supplier information provides a reliable basis. Design qualification supplier performance ability to verify and tender linkage scheme main work content is as follows:

(1) No difference with database content suppliers, according to the evaluation scheme and results of qualification verification standard, clear linkage factor and linkage calculation formula of calculating every linkage factor score, according to various weight eventually concluded that certain material supplier business evaluation and technology, and import materials respectively tender business in partial evaluation and technical part.

(2) For suppliers and information content is different, the bid evaluation experts inform difference suppliers to provide supporting materials, the bid evaluation experts according to the evidence materials scores;

(3) to temporarily not involved in supplier performance verification of qualification of suppliers, through setting the basic points of the score, the default giving suppliers basic points, after using ECP query to verify information, supplier provide documents to verify the information, to visit the factory site verification to adjust basic points. 


\section{Supplier Performance Evaluation and Bidding Linkage Scheme Design}

Supplier performance evaluation is to supervise the supplier sign in procurement, manufacturing, transportation, delivery, installation, debugging, maintenance operation each link of the performance and evaluation on the performance of the contract. Supplier performance evaluation and the tender gang was established according to the historical performance of linkage content: evaluating the performance ratings by the grass-roots projects, from good to bad step in all valid bidder, past performance is good, it complain record of 30 points, the worst 15 points. No record to the suppliers to set the basic points. (See figure 2).

Figure 2. Supplier performance evaluation and bidding linkage scheme

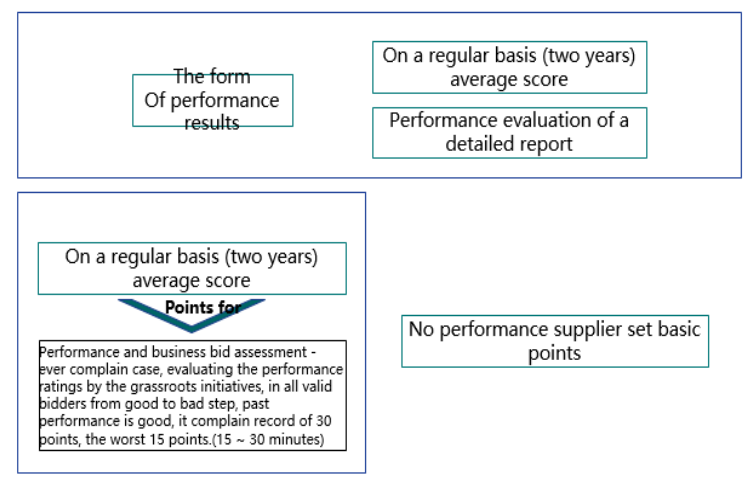

\section{Deal With Tender Linkage Scheme Supplier Bad Behavior}

Supplier bad behavior treatment is to find and verify materials management, supplier in participate in the bidding procurement activities and in the process of contract implementation, in response to tender, product manufacturing, shipping transportation, acceptance of delivery, installation and debugging, operation maintenance of the integrity, management of the delivery and quality problems. Supplier bad behavior with tender linkage design mainly through our company supplies supervision department collection problem, form a formal bad behavior record form, according to the nature of the problem by the materials department related departments accordingly.

\section{E. The Factor Analysis Approach, Determine The Linkage}

Through a commercial grade rules and technical conditions set in the closed loop linkage curing rate evaluation factor, supplier management achievement and the tender linkage strategies for curing (figure 3). Supplier quality performance evaluation factors are divided into commercial evaluation factors and technical evaluation factors.
Figure 3. Determine the interaction factor

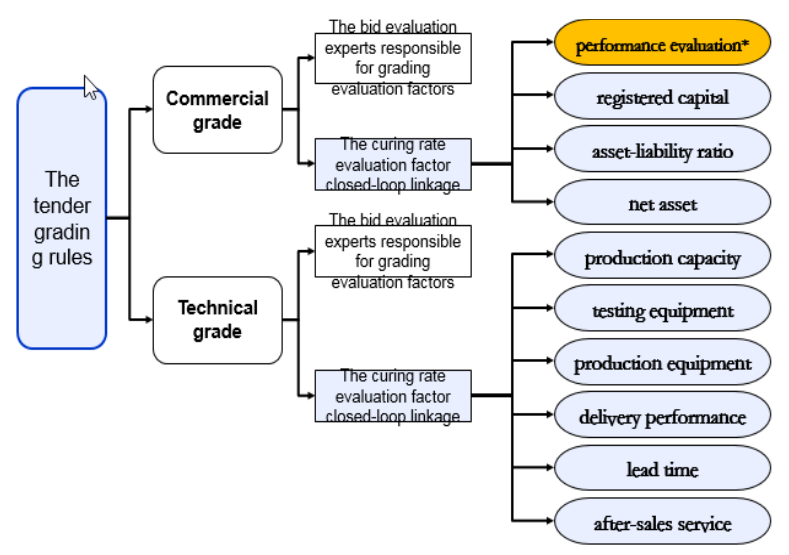

\section{F. Establishing Standards For Closed-Loop Linkage}

The quarterback method in applied statistics, the establishment of bidding closed-loop linkage standard. In the registered capital, for example, according to the material category to determine the basic requirements, to meet the basic requirements of all the suppliers to verify according to the registered capital from big to small order, Among them:

A: the top $15 \%$ of the suppliers, score $=20+20 \times 100 \%$ $=40$ points;

B: from $50 \%$ to $15 \%$ of the top suppliers, $=20+20 \times 60 \%$ $=32$ points;

C: from $85 \%$ to $50 \%$ of the top suppliers, score $=20+$ $20 \times 30 \%=26$ points;

D: from $100 \%$ to $85 \%$ of the top suppliers, $=20+20 \times 0 \%$ $=20$ points.

Set up the basic points of all the evaluation items. For temporary work performance was not involved in supplier qualification and verification, the supplier, the evaluation of the default as the basic points, and the qualification results after check reference with the scores level supplier.

Through analysis it is concluded that: the weight of different types of supplies business scale factor and general, different kind's supplies technical grading index weights are different.

\section{THE ELECTRIC POWER ENTERPRISE SUPPLIER} MANAGEMENT LINKAGE AND BID PROCUREMENT STRATEGY AND THE KEY TECHNOLOGIES OF APPLICATION RESEARCH

Achievements of the electric power enterprise supplier management and bidding procurement linkage strategies applied research is by studying a variety of procurement mode applicable conditions, on the basis of the characteristics of the power supplies of bidding and bid evaluation model, a clear supplier management and the relationship between the results with the current bidding work and way of application, including the quality control, cost control and production control achievements of supplier management and bidding model of the linkage.

Linkage factor is the basis of the procurement sourcing and supply strategies research with difficulty. Because there are many different kinds of materials of the electric power 
industry, and many materials with special physical characteristics and technical requirements, how to according to the characteristics of Shanghai electric power company needed supplies, especially the physical properties and technical characteristics of linkage factor is difficult to determine. This results in order to solve this difficult problem, adopt the method of Delphi method and technology research group, Shanghai electric Power Company involved in materials and the future is likely to involve the generality of supplies reasonable induction and classification. Closely with enterprise leadership and the management ideas at the same time, makes the linkage model has practicability and expansibility.

The design of the grading rules are essential elements of linkage model. The design of the grading rules directly affects the operability of the model and the scientific nature. For how to determine the power supplies with different properties criteria, there is no related research. This research USES the Delphi survey method, through to the supply chain of electric power and electric power production experts' questionnaires to determine the key material grading rules. At the same time, the quarterback method in applied statistics, set up the quantitative linkage standard of conventional linkage factor.

\section{SUMMARY AND OUTLOOK}

Electric power enterprise supplier management and bidding procurement linkage strategies applied research to further deepen the supplier relationship management, on supplier performance evaluation and qualification verification analysis, supplier qualification, equipment, production capacity of on-site verification results have been formed system, direct reference in the process of the evaluation score, organize regular meeting results application effect of expert commenting, improve the results of application.

The benefit and effect of application is mainly manifested in the following areas:

1. Through a policy, system, process, and the form of curing, the establishment of a complete bidding procurement standard mode, standardizes the supplier management achievement and the tender gang work, improve the efficiency of the bidding work.

2. The results in the process of the implementation of application, set up a complete set of supplier qualification, equipment, production capacity of the systematics of the onsite verification results, on the supplier's production capacity, equipment conditions, history score has carried on the quantitative project such as supply situation, and apply the results to the material in the process of bidding the intern and detailed evaluation link, reduced the subjective factors impact on the evaluation of bid evaluation experts, to ensure the fairness of the evaluation.

3. The results of supplier management and purchasing way the relations and applications of the method, a full set of the application of research results in the tender part implements the supplier qualification performance verification, and supplier performance evaluation and the linkage of the bidding, greatly improved the supplier management of the supplier of the binding.

Bad behavior processing standards on the basis of research achievements of suppliers, supplier for wrongdoing by the company for punishment. At the same time, the results of punishment are applied to the evaluation process, and the public, effectively curb the bad behavior of supplier. Effectively curb the bad behavior of supplier, guarantee the quality of the power supplies, benign for power supplies in procuring supplies and suppliers the establishment of harmonious relationship provides a solid foundation. Bad behavior processing standards on the basis of research achievements of suppliers, supplier for wrongdoing by the company for punishment. At the same time, the results of punishment are applied to the evaluation process, and the public, effectively curb the bad behavior of supplier. Effectively curb the bad behavior of supplier, guarantee the quality of the power supplies, benign for power supplies in procuring supplies and suppliers the establishment of harmonious relationship provides a solid foundation.

4. Combined with the company system reform carried out in 2013, the electric power enterprise supplier management and bidding procurement linkage strategies applied research as an important part of company supplier management strategy, and implanted the company information system, to comprehensively improve the work efficiency of material purchasing and supplier management and benefit, comprehensively promote the company supplies intensive management plays an important role.

\section{REFERENCE}

[1] James R. Taylor, Charles C. Tucker. Reducing Data Processing Costs through Centralized Procurement [J]. MIS Quarterly, 1989, 13(4): 487-499.

[2] Ralph G. Kaufman. Procurement Manual [M], Beijing: China Machine Press, 2001.

[3] M. Jae Moon. E-procurement Management in State Governments: Diffusion of E-procurement Practices and its Determinant $[\mathrm{J}]$. Journal of Public Procurement, 2005, 5(1): 54-72.

[4] Emiko Benfield. MSc Strategic Procurement Management $[\mathrm{M}]$. China financial economic publishing, 2005.13-20,179-183.

[5] Sixin Xie, Bo Wang. Patterns and strategies on the implementation of centralized purchasing in China [J], Railway Purchase and Logistics, 2007, 9:6-8. 